\title{
Molecular epizootiology of Perkinsus marinus and P. chesapeaki infections among wild oysters and clams in Chesapeake Bay, USA
}

\author{
Kimberly S. Reece ${ }^{1, *}$, Christopher F. Dungan ${ }^{2}$, Eugene M. Burreson ${ }^{1}$ \\ ${ }^{1}$ College of William and Mary, Virginia Institute of Marine Science, PO Box 1346, Gloucester Point, Virginia 23062, USA \\ ${ }^{2}$ Maryland Department of Natural Resources, Cooperative Oxford Laboratory, 904 S. Morris St., Oxford, Maryland 21654, USA
}

\begin{abstract}
Perkinsus marinus and P. chesapeaki host ranges among wild Chesapeake Bay, USA, region bivalves were examined by surveying Crassostrea virginica oysters and members of several sympatric clam species from 11 locations. Perkinsus genus- and species-specific PCR assays were performed on DNA samples from 731 molluscs, and species-specific in situ hybridization assays were performed on a selected subset of histological samples whose PCR results indicated dual or atypical Perkinsus sp. infections. PCR assays detected P. marinus in $92 \%$ of oysters, but the P. chesapeaki PCR assay was positive for only $6 \%$ of oysters, and $P$. marinus was detected by PCR in only one clam. The very low prevalence of $P$. marinus infections in clams is noteworthy because all surveyed clams were sympatric with oyster populations showing high $P$. marinus infection prevalences. P. chesapeaki commonly infected Mya arenaria, Macoma balthica, and Tagelus plebeius clams, as well as the previously unreported P. chesapeaki host clams Mulinia lateralis, Rangia cuneata, and Cyrtopleura costata. Among 30 in vitro isolates propagated from surveyed hosts, 8 P. marinus isolates were exclusively from Crassostrea virginica oysters, and all 22 P. chesapeaki isolates were from clam hosts of 5 different species. Although both $P$. marinus and $P$. chesapeaki were previously both shown to be experimentally infective for oyster and clam hosts, this survey of wild bivalves in the Chesapeake Bay region reveals that $P$. marinus infections occur almost exclusively in oysters, and $P$. chesapeaki infections predominate among members of at least 6 clam species.
\end{abstract}

KEY WORDS: Parasite - Diagnostic assays · PCR · Internal transcribed spacer · Large subunit ribosomal RNA · ITS · LSU rRNA · Histology · In vitro isolates · In situ hybridization

\section{INTRODUCTION}

Closely following the original description of Perkinsus marinus (= Dermocystidium marinum) as a prevalent pathogen of Crassostrea virginica oysters in the Gulf of Mexico (Mackin et al. 1950), C. virginica oysters and several species of clams in Chesapeake Bay, USA, waters were reported to be similarly infected (Andrews 1954, Ray \& Chandler 1955). A distinctive Perkinsus sp. was subsequently reported to infect Macoma balthica clams in Chesapeake Bay (Valiulis \& Mackin 1969), and years later a parasite from that clam host was described as P. andrewsi (Coss et al. 2001).
Perkinsus sp. infections were reported to be prevalent among Chesapeake Bay commercial clams Mya arenaria (McLaughlin \& Faisal 2000) and Tagelus plebeius (Dungan et al. 2002), and a parasite of $M$. arenaria was described as $P$. chesapeaki (McLaughlin et al. 2000). P. andrewsi was subsequently recognized to be a junior synonym of $P$. chesapeaki, and the host range of $P$. chesapeaki was extended to include both $T$. plebeius and Macoma balthica clams in Chesapeake Bay (Burreson et al. 2005). Therefore, only P. marinus and $P$. chesapeaki are currently recognized as coendemic Perkinsus spp. parasites of diverse, sympatric bivalve molluscs in Chesapeake Bay waters. 
Histological and Ray's fluid thioglycollate medium (RFTM) (Ray 1952) assays have been used historically for detection of Perkinsus sp. infections in molluscan tissues, although neither assay discriminates among Perkinsus species. Therefore, the specific identities of parasites detected by these generic assays are ambiguous in regions where multiple Perkinsus spp. are endemic. Species-specific PCR assays have been developed that allow sensitive detection and discrimination of Perkinsus sp. DNAs from host tissue samples (Marsh et al. 1995, Robledo et al. 1998, Yarnall et al. 2000, Burreson et al. 2005, Gauthier et al. 2006, Moss et al. 2006) and from environmental samples (Audemard et al. 2004). Based on PCR results, both P. marinus and $P$. chesapeaki are inferred to infect or co-infect several sympatric Chesapeake Bay bivalve molluscs (Kotob et al. 1999, Coss et al. 2001). PCR assays, however, target the DNA from parasite cells, and may detect DNA from both non-viable pathogen cells as well as from those that may be only transiently associated with host tissue samples. Positive results from PCR assays must be interpreted cautiously, and cannot rigorously confirm active infections in the absence of supporting or confirmatory in situ evidence (Burreson 2008).

Recent experimental results confirm that high-dose laboratory challenges of several sympatric species of Chesapeake Bay molluscs with axenic, in vitro Perkinsus marinus or $P$. chesapeaki cells yielded high incidences of infections by both pathogen species in Crassostrea virginica oysters and in Mya arenaria and Macoma balthica clams (Dungan et al. 2007). Those experimental results are strikingly inconsistent with the apparent narrow host specificities of $P$. marinus and $P$. chesapeaki suggested by the nearly exclusive in vitro propagation of $P$. chesapeaki from diverse Chesapeake Bay clam species, and the exclusive propagation of $P$. marinus from Chesapeake Bay oysters (La Peyre et al. 2006).

To determine the primary (i.e. dominant) host ranges for Perkinsus marinus and $P$. chesapeaki among wild Chesapeake Bay bivalve molluscs, we report results of a survey that sampled Crassostrea virginica oysters and at least 1 (among 6) species of sympatric clams at 11 locations throughout Maryland and Virginia waters in the Chesapeake Bay region. Parasite species-specific PCR assays were performed on DNAs that were available from most sampled mollusc hosts, and species-specific confirmatory in situ hybridization (ISH) assays and histopathological assays were performed on histological sections from a selected subset of those host tissues. In addition, 30 Perkinsus spp. isolates that were propagated in vitro from 1 oyster species and 5 clam host species were characterized.

\section{MATERIALS AND METHODS}

Mollusc samples. Samples of wild, sympatric, subtidal adult oysters and clams were collected with hydraulic escalator dredge, vacuum dredge, or patent tongs from 11 Chesapeake Bay region locations during the summers of 2001，2002, and 2003 (Fig. 1, see Table 1). Samples of 25 to 30 bivalve molluscs of each collected species were attempted, but smaller opportunistic samples of some clam species were also collected and analyzed. Wild Crassostrea virginica oysters were collected at each sample site from a variety of substrates including shell reefs, pilings, riprap, bulkheads, and mud, depending on site, along with 1 to 4 species of sympatric clams that were collected locally from soft benthic substrates. For 10 of 11 sample sites, diameters of sampled areas were $4 \mathrm{~km}$ or less, while the diameter of Site 7 (Patuxent River, Maryland) was $15 \mathrm{~km}$. Except at Site 7, samples collected by hydraulic escalator dredge or patent tongs included both oysters and clams that were collected simultaneously from the same benthic substrate. When a vacuum dredge was

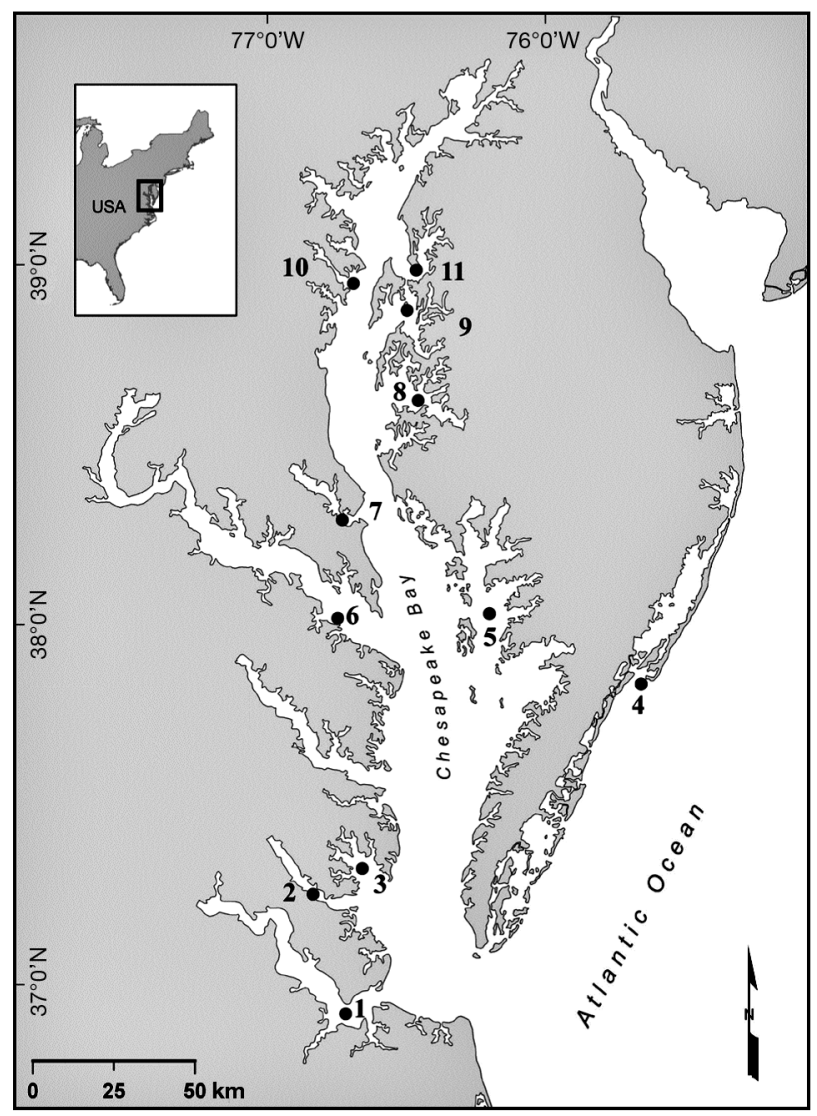

Fig. 1. Numbered sampling sites in the Chesapeake Bay region for sympatric oyster and clam species collected and analyzed for Perkinsus marinus and $P$. chesapeaki during 2001-2003. Site locations and sampled species are listed in Table 1 
used to collect clam samples from soft and shallow benthic substrates (Site 2, York River, Virginia), oysters were collected from adjacent hard substrates. Sampled clam species included Mya arenaria, Tagelus plebeius, Mercenaria mercenaria, Macoma balthica, Mulinia lateralis, Rangia cuneata, Cyrtopleura costata, and Barnea truncata (see Table 1). Live samples were returned to laboratories at Gloucester Point, Virginia (VIMS) or Oxford, Maryland (MD DNR) for acquisition, preservation, and analysis of tissue samples. A total of 757 individuals were processed for analyses, and DNA samples for PCR assays were obtained from 731 oysters or clams.

Tissue samples. Live molluscs were sacrificed, and tissue samples were aseptically excised and preserved for PCR, RFTM, and histological diagnostic assays, as well as for in vitro Perkinsus sp. isolate propagation. Mollusc tissue for DNA extractions and subsequent PCR assays were collected by aseptic excision with ethanol-flamed instruments. Samples of mantle, gill, gonad, and visceral tissues were placed in sterile tubes containing 10 volumes of absolute ethanol. Parallel transverse histological tissue samples were excised, preserved for $48 \mathrm{~h}$ in Davidson's AFA fixative (Shaw \& Battle 1957), and processed by standard methods for paraffin histology. Mantle, gill, and/or visceral tissues were aseptically excised for use as inocula for in vitro Perkinsus sp. isolate cultures and RFTM assays to estimate Perkinsus sp. infection prevalences of samples, and relative infection intensities of individual molluscs.

RFTM assays. From each sampled mollusc, duplicate gill and mantle (clams) or rectum and mantle (oysters) tissue biopsies were inoculated into $2 \mathrm{ml}$ of RFTM in wells of duplicate 24-well culture plates. RFTM was supplemented with penicillin $\left(200 \mathrm{U} \mathrm{ml}^{-1}\right)$, streptomycin $\left(200 \mu \mathrm{g} \mathrm{ml}^{-1}\right)$, gentamicin $\left(200 \mu \mathrm{g} \mathrm{ml}^{-1}\right)$, chloramphenicol $\left(50 \mu \mathrm{g} \mathrm{ml}^{-1}\right)$, and nystatin $\left(50 \mathrm{U} \mathrm{ml}^{-1}\right)$ to selectively inhibit growth of bacterial and fungal associates. Plates were incubated for 48 to $96 \mathrm{~h}$ at $27^{\circ} \mathrm{C}$ before tissues in wells of one replicate plate were stained with $30 \%$ (v/v) Lugol's iodine for microscopic enumeration of enlarged Perkinsus sp. hypnospores. Categorical infection intensities of sampled molluscs were rated on a scale of 0 (absent) to 5 (very heavy) (Dungan et al. 2002) and for each sample a mean infection intensity was calculated as the sum of the categorical infection intensities of each infected individual divided by the number of infected individuals in the sample (Bush et al. 1997). Based on high infection intensities estimated by RFTM assays, enlarged Perkinsus sp. hypnospores from duplicate, unstained tissues of selected sampled molluscs were used as inocula for propagation of Perkinsus sp. in vitro isolate cultures (La Peyre \& Faisal 1995).
In vitro pathogen propagation. For in vitro isolate culture inocula, RFTM was aspirated from selected Perkinsus sp.-infected experimental tissues, and enlarged parasite hypnospores were released into suspension by trituration of tissues in $2 \mathrm{ml}$ of $850 \mathrm{mOsm}$ $\mathrm{kg}^{-1}$ Dulbecco's modiefied Eagles (DME):Ham's F-12 Perkinsus sp. culture medium (DME/F12-3) that was supplemented with antimicrobials as described for RFTM (Burreson et al. 2005). Resulting inoculum suspensions were serially diluted into DME/F12-3 medium in 4 wells of a 24 -well culture plate, and incubated at $27^{\circ} \mathrm{C}$ with daily microscopic observation for Perkinsus sp. proliferation. Proliferating isolate cultures were expanded in culture flasks and viable isolate cells were cryopreserved. In vitro isolates whose DNAs were sequenced were cloned by limiting dilution plating before DNA extractions, and cloned isolate strains were cryopreserved (Dungan et al. 2007).

PCR assays and sequencing of amplification products. DNA was extracted from ethanol-preserved mollusc host tissues $\left(\sim 0.25 \mathrm{~cm}^{3}\right.$ piece) and from cells of the axenic Perkinsus spp. isolates generated during this investigation. Host tissue and in vitro parasite cell DNAs were both extracted using the Qiagen DNAeasy Tissue Kit (Invitrogen) following the manufacturer's protocol, and were used as templates in separate amplifications by each of the 3 diagnostic PCR assays employed.

All PCR primers were from Invitrogen. Perkinsus genus-specific PCR assays (85-750-ITS) were performed with methods and primers targeting rDNA sequences that are conserved among all known Perkinsus species except $P$. qugwadi (incertae sedis) (Casas et al. 2002). PCR assays to test for the presence of $P$. marinus DNA were done with $P$. marinus-specific primers (Pmar-ITS) (Audemard et al. 2004), and $P$. chesapeaki-specific primers (Pches-ITS) (Burreson et al. 2005) were used to test for the presence of P. chesapeaki DNA. For further genetic characterization, an approximate $900 \mathrm{bp}$ fragment of the large subunit ribosomal RNA gene (LSU rRNA) was amplified from DNA of selected in vitro parasite cells for sequence analyses, using the primers LSU-A (forward; 5'-ACC CGC TGA ATT TAA GCA TA-3') and LSU-B (reverse; 5'-ACG AAC GAT TTG CAC GTC AG-3') (Lenaers et al. 1989). Amplifications were performed in $25 \mu \mathrm{l}$ reactions as previously described for the ITS region (Dungan et al. 2007) and the LSU rRNA gene fragment (Burreson et al. 2005), except that reactions for each sample at each locus were conducted in duplicate with undiluted ( 50 to $300 \mathrm{ng}$ genomic DNA obtained from the isolation protocol, and at $1 / 10$ dilution ( 5 to $30 \mathrm{ng}$ ) of template DNAs. The PCR products were identified and differentiated by size using agarose gel (2\%) electrophoresis. To confirm Perkinsus spp. identities and assay speci- 
ficities, selected amplification products from host tissue and clonal in vitro isolate culture DNAs were sequenced by simultaneous bi-directional cyclesequencing (see Table 1) as previously described (Reece \& Stokes 2003).

Histological, digoxigenin (DIG)-ISH, and fluorescence in situ hybridization (FISH) assays. For histopathological analyses, sections of paraffin-embedded tissue samples were cut at 5 to $6 \mu \mathrm{m}$ and dried onto poly-L-lysine coated microscope slides, where sections were dewaxed, rehydrated, and stained with Mayer's hematoxylin and eosin (H\&E).

For DNA probe ISH, either DIG-labeled probes or fluorescent probes were used on histological sections that were collected and dried on silanized slides (Colorfrost Plus, Fisher Scientific) from tissues of selected survey molluscs whose PCR assay results indicated a Perkinsus sp. infection in a host where it had not been previously reported, and/or infections by more than one Perkinsus sp. Dewaxed and rehydrated sections were hybridized with appropriate DNA probes.

ISHs were done on serial sections of tissues from selected Crassostrea virginica oysters that were PCRpositive for both Perkinsus marinus and P. chesapeaki using DIG-labeled probes (Operon Biotechnologies). The 3 probes included a (1) Perkinsus genus-specific antisense small subunit ribosomal RNA (SSU rRNA) gene probe, PerkspSSU-700DIG (5'-CGC ACA GTT AAG TRC GTG RGC ACG-3') (Elston et al. 2004); (2) $P$. marinus-specific antisense LSU rRNA gene probe, PmarLSU-181DIG (5'-GAC AAA CGG CGA ACG ACT C-3'); and (3) P. chesapeaki-specific antisense LSU-rRNA gene probe, PchesLSU-485DIG (5'-CAG GAA ACA CCA CGC ACK AG-3'). The protocol followed for DIG-ISH was as previously published (Stokes \& Burreson 1995), with the modifications specified in Elston et al. (2004). A probe concentration of $7 \mathrm{ng} \mathrm{\mu l}^{-1}$ was used for hybridization with both the genus- and species-specific DIG-labeled probes. As with the previously tested and published $P$. marinusspecific probe (Moss et al. 2006), the P. chesapeakispecific probe was tested for specificity against Perkinsus sp.-infected reference tissues, including $P$. marinus in Crassostrea virginica, $P$. chesapeaki in Mya arenaria, $P$. mediterraneus in Chamelea gallina, P. olseni in Venerupis (=Tapes) philippinarum, and P. honshuensis in $V$. philippinarum.

Histological tissue sections from several Cyrtopleura costata clams that were PCR-positive for Perkinsus chesapeaki and tissue sections from a Mya arenaria clam that was PCR-positive for $P$. marinus were both screened by FISH, using probe cocktails that were respectively specific for $P$. chesapeaki or $P$. marinus. The $P$. marinus-specific cocktail consisted of 3 greenfluorescent Alexa Fluor 488-labeled anti-sense LSU
rRNA gene probes; PmarLSU-181, PmarLSU-420 (5'GAA GAC AGG AGC GAG CAG C-3') and PmarLSU560 (5'-AAC CAA TTC ACA GAT AGC G-3'). The $P$. chesapeaki-specific cocktail consisted of 2 red-fluorescent Alexa Fluor 594-labeled anti-sense LSU rRNA gene probes; PchesLSU-485 and PchesLSU-690 (5'GCG AGC AAT CTT AGA GCC-3'). Control sections were used to test the specificities of each of the FISH probe cocktails. These included a section from a Chesapeake Bay Crassostrea virginica oyster coinfected by both $P$. marinus and Haplosporidium nelsoni, and from a Chesapeake Bay $M$. arenaria clam infected by $P$. chesapeaki.

The FISH protocol was conducted according to Carnegie et al. (2006), except that the initial permeabilization step was done by a $30 \mathrm{~min}$ incubation with pronase at a final concentration of $1.25 \mathrm{mg} \mathrm{ml}^{-1}$. The individual probe concentrations in the Perkinsus marinus-specific FISH cocktail were $6.5 \mathrm{ng}^{-1} \mathrm{l}^{-1}$, while for the $P$. chesapeaki-specific cocktail they were $3 \mathrm{ng}^{-1} \mathrm{l}^{-1}$. For all DIG-ISH and FISH assays, negative controls included serial histological sections of the tested samples that received hybridization buffer without probe during hybridization incubations. In addition, specificity of the P. marinus- and P. chesapeaki-specific FISH cocktails was tested by hybridizing speciesspecific probes to sections of control tissues infected by the opposite parasite species.

\section{RESULTS}

The ribosomal DNA internal transcribed spacer (ITS) region PCR primers specific for Pmar-ITS and PchesITS amplified 509 and 554 bp PCR products, respectively. In most individuals where positive results were obtained, both full-strength and diluted (1/10) DNA resulted in amplification products. There was less consistency, however, with results of PCR reactions conducted with diluted and undiluted DNAs from the clam samples. Among clam sample DNAs, some positive reactions $(\sim 20 \%)$ were only observed with diluted template DNAs, suggesting the presence of PCR inhibitors in those DNA samples.

Among 279 Crassostrea virginica oysters tested by PCR assays, $92 \%$ (257) harbored Perkinsus marinus DNA, and $6 \%$ (17) additionally harbored P. chesapeaki DNA. No tested oyster harbored only P. chesapeaki (Table 1). Oyster samples harboring apparent co-infections by $P$. marinus and $P$. chesapeaki at 20 to $28 \%$ prevalences were found at 3 sites (Mobjack Bay, Virginia; Potomac River, Maryland; and Upper Bay, Maryland) spanning nearly the entire geographic range of oyster populations in Chesapeake Bay (Fig. 1, Sites 3, 6 , and 10). Eight in vitro isolates that were propagated 
Table 1. Sympatric oyster and clam samples from 11 sites (see Fig. 1). Sampling sites and collection years for each sample are given. VA: Virginia; MD: Maryland. Unless otherwise indicated (years in parentheses following species names), all host species were collected at the same time. Perkinsus spp. infection prevalences (\%) were estimated by generic Ray's fluid thioglycollate medium (RFTM) assays, a Perkinsus genusspecific internal transcribed spacer (ITS)-PCR assay, a P. marinus-specific ITS-PCR assay, a $P$. chesapeaki-specific ITS-PCR assay, or not done (-). Mean infection intensity (Inf) for each sample as determined by the RFTM assay is given in parentheses. na: not applicable

\begin{tabular}{|c|c|c|c|c|c|c|c|c|}
\hline $\begin{array}{l}\text { Site } \\
\text { no. }\end{array}$ & $\begin{array}{l}\text { Site } \\
\text { diameter } \\
(\mathrm{km})\end{array}$ & $\begin{array}{l}\text { Location } \\
\text { (year) }\end{array}$ & $\begin{array}{l}\text { Species } \\
\text { sampled }\end{array}$ & $\begin{array}{l}\text { Sample } \\
\text { (n) }\end{array}$ & $\begin{array}{l}\text { Genus } \\
\text { Perkinsus } \\
\text { RFTM } \\
\text { (Inf) }\end{array}$ & $\begin{array}{l}\text { Genus } \\
\text { Perkinsus } \\
\text { ITS-PCR }\end{array}$ & $\begin{array}{l}\text { P. marinus } \\
\text { ITS-PCR }\end{array}$ & $\begin{array}{l}\text { P. chesapeaki } \\
\text { ITS-PCR }\end{array}$ \\
\hline 1 & $<1$ & $\begin{array}{l}\text { VA, James River, } \\
\text { Newport News } \\
(2003)\end{array}$ & $\begin{array}{l}\text { Crassostrea virginica } \\
\text { Mya arenaria } \\
\text { Tagelus plebeius }\end{array}$ & $\begin{array}{l}24 \\
25 \\
25\end{array}$ & $\begin{array}{l}54(2.1) \\
20(1.0) \\
24(1.0)\end{array}$ & $\begin{array}{l}50 \\
68 \\
16\end{array}$ & $\begin{array}{c}50 \\
4 \\
0\end{array}$ & $\begin{array}{c}0 \\
16 \\
16\end{array}$ \\
\hline 2 & 2 & $\begin{array}{l}\text { VA, York River, } \\
\text { Kings Creek \& } \\
\text { Felgates Creek (2002) }\end{array}$ & $\begin{array}{l}\text { Crassostrea virginica } \\
\text { Tagelus plebeius } \\
\text { Macoma balthica }\end{array}$ & $\begin{array}{l}30 \\
30 \\
29\end{array}$ & $\begin{aligned} 100 & (3.6) \\
0 & (\text { na) } \\
37 & (1.9)\end{aligned}$ & $\begin{array}{c}100 \\
0 \\
73\end{array}$ & $\begin{array}{c}100 \\
0 \\
0\end{array}$ & $\begin{array}{c}0 \\
0 \\
73\end{array}$ \\
\hline 3 & 4 & $\begin{array}{l}\text { VA, Mobjack Bay, Ware } \\
\text { River \& North River } \\
(2002)\end{array}$ & $\begin{array}{l}\text { Crassostrea virginica } \\
\text { Mercenaria mercenaria }\end{array}$ & $\begin{array}{l}30 \\
30\end{array}$ & $\begin{array}{r}100(3.0) \\
3(1.0)\end{array}$ & $\begin{array}{c}97 \\
0\end{array}$ & $\begin{array}{c}97 \\
0\end{array}$ & $\begin{array}{c}20 \\
0\end{array}$ \\
\hline 4 & $<1$ & $\begin{array}{l}\text { VA, Chincoteague Bay, } \\
\text { Tom's Cove (2002) }\end{array}$ & $\begin{array}{l}\text { Crassostrea virginica } \\
\text { Mercenaria mercenaria }\end{array}$ & $\begin{array}{l}30 \\
30\end{array}$ & $\begin{array}{c}100(3.1) \\
0 \text { (na) }\end{array}$ & $\begin{array}{l}90 \\
90\end{array}$ & $\begin{array}{l}0 \\
0\end{array}$ & $\begin{array}{l}0 \\
0\end{array}$ \\
\hline 5 & 1 & $\begin{array}{l}\text { MD, Tangier Sound, } \\
\text { Terrapin Sands (2002) }\end{array}$ & $\begin{array}{l}\text { Crassostrea virginica } \\
\text { Mya arenaria } \\
\text { Cyrtopleura costata } \\
\text { Barnea truncata }\end{array}$ & $\begin{array}{c}25 \\
25 \\
9 \\
10\end{array}$ & $\begin{aligned} 52 & (2.5) \\
0 & (\text { na) } \\
0 & (\mathrm{na}) \\
10 & (1.0)\end{aligned}$ & $\begin{array}{c}88 \\
0 \\
- \\
-\end{array}$ & $\begin{array}{c}88 \\
0 \\
- \\
-\end{array}$ & $\begin{array}{l}0 \\
0 \\
- \\
-\end{array}$ \\
\hline 6 & 1 & $\begin{array}{l}\text { MD, Potomac River, } \\
\text { Bonums Creek (2002) }\end{array}$ & $\begin{array}{l}\text { Crassostrea virginica } \\
\text { Mya arenaria } \\
\text { Tagelus plebeius } \\
\text { Cyrtopleura costata }\end{array}$ & $\begin{array}{c}19 \\
25 \\
5 \\
4\end{array}$ & $\begin{array}{r}95(1.8) \\
100(3.0) \\
100(2.4) \\
100(1.0)\end{array}$ & $\begin{array}{c}100 \\
84 \\
80 \\
100\end{array}$ & $\begin{array}{c}100 \\
0 \\
0 \\
0\end{array}$ & $\begin{array}{l}21 \\
84 \\
80 \\
75\end{array}$ \\
\hline 7 & 15 & $\begin{array}{l}\text { MD, Patuxent River, } \\
\text { Broomes Island \& Drum } \\
\text { Cliff }(2001,2002)\end{array}$ & $\begin{array}{l}\text { Crassostrea virginica } \\
\text { Mya arenaria } \\
\text { Tagelus plebeius } \\
\text { Rangia cuneata }(2001)\end{array}$ & $\begin{array}{l}25 \\
25 \\
25 \\
12\end{array}$ & $\begin{array}{r}88(2.7) \\
84(2.0) \\
100(2.5) \\
100(2.1)\end{array}$ & $\begin{array}{c}88 \\
48 \\
84 \\
-\end{array}$ & $\begin{array}{c}88 \\
0 \\
0 \\
-\end{array}$ & $\begin{array}{c}0 \\
28 \\
84 \\
-\end{array}$ \\
\hline 8 & $<1$ & $\begin{array}{l}\text { MD, Choptank River, } \\
\text { Bolingbroke Sands (2002) }\end{array}$ & $\begin{array}{l}\text { Crassostrea virginica } \\
\text { Mya arenaria } \\
\text { Tagelus plebeius }\end{array}$ & $\begin{array}{l}25 \\
25 \\
25\end{array}$ & $\begin{array}{l}100(3.6) \\
100(4.2) \\
100(3.6)\end{array}$ & $\begin{array}{c}96 \\
80 \\
100\end{array}$ & $\begin{array}{c}96 \\
0 \\
0\end{array}$ & $\begin{array}{c}0 \\
80 \\
88\end{array}$ \\
\hline 9 & 3 & $\begin{array}{l}\text { MD, Eastern Bay, Parsons } \\
\text { Island \& Narrow Point } \\
(2001,2002)\end{array}$ & $\begin{array}{l}\text { Crassostrea virginica } \\
\text { Mya arenaria } \\
\text { Tagelus plebeius } \\
\text { Macoma balthica (2001) } \\
\text { Mulinia lateralis (2001) }\end{array}$ & $\begin{array}{c}23 \\
25 \\
25 \\
3 \\
2\end{array}$ & $\begin{array}{l}100(3.3) \\
100(2.6) \\
100(1.3) \\
100(1.0) \\
100(1.5)\end{array}$ & $\begin{array}{l}100 \\
92 \\
64 \\
- \\
-\end{array}$ & $\begin{array}{c}100 \\
0 \\
0 \\
- \\
-\end{array}$ & $\begin{array}{l}0 \\
28 \\
48 \\
- \\
-\end{array}$ \\
\hline 10 & 4 & $\begin{array}{l}\text { MD, Upper Bay, Hacketts } \\
\text { \& Sandy Point (2002) }\end{array}$ & $\begin{array}{l}\text { Crassostrea virginica } \\
\text { Mya arenaria } \\
\text { Macoma balthica }\end{array}$ & $\begin{array}{c}25 \\
25 \\
7\end{array}$ & $\begin{array}{r}100(3.6) \\
96(1.7) \\
100(2.0)\end{array}$ & $\begin{array}{c}100 \\
72 \\
100\end{array}$ & $\begin{array}{c}100 \\
0 \\
0\end{array}$ & $\begin{array}{c}28 \\
60 \\
100\end{array}$ \\
\hline 11 & 1 & $\begin{array}{l}\text { MD, Chester River, Buoy } \\
\text { Rock (2002) }\end{array}$ & $\begin{array}{l}\text { Crassostrea virginica } \\
\text { Mya arenaria } \\
\text { Tagelus plebeius }\end{array}$ & $\begin{array}{l}25 \\
25 \\
22\end{array}$ & $\begin{array}{r}100(2.7) \\
100(1.3) \\
96(1.7)\end{array}$ & $\begin{array}{c}100 \\
80 \\
86\end{array}$ & $\begin{array}{c}100 \\
0 \\
0\end{array}$ & $\begin{array}{c}0 \\
16 \\
91\end{array}$ \\
\hline
\end{tabular}

from C. virginica oysters collected at 2 distant sites (Eastern Bay and Patuxent River, Maryland) were exclusively identified as $P$. marinus, based on PCR results and rRNA complex ITS-region and LSU rRNA gene sequences that were deposited in GenBank (Tables $2 \& 3$ ).

PCR assays indicated a nearly complete absence of Perkinsus marinus infections among 452 clams that were tested from 5 species, despite the close sympatric cohabitation of all sampled clams with oyster popula- tions that showed high prevalences of $P$. marinus infections $(50$ to $100 \%$, mean $=92 \%)($ Table 1$)$. Among clams that were tested by PCR assays, 55\% (253) were positive by the Perkinsus genus-specific PCR assay, while $42 \%$ (192) were positive for $P$. chesapeaki DNA, including 3 of 4 Cyrtopleura costata, from which $P$. chesapeaki has not been previously reported. Generic RFTM assays similarly indicated an overall prevalence of $61 \%$ (280) of Perkinsus sp. cells among all clam samples. Amplification products from the Perkinsus genus- 
Table 2. Perkinsus spp. in vitro isolates propagated from Chesapeake Bay oysters and clams. Accession codes are listed for ATCC-deposited isolates, including those from clam species $\left({ }^{*}\right)$ not previously reported as $P$. chesapeaki hosts

\begin{tabular}{|c|c|c|c|c|}
\hline $\begin{array}{l}\text { Site } \\
\text { no. }\end{array}$ & Host & $\begin{array}{c}\text { Perkinsus } \\
\text { marinus } \\
\text { isolates }\end{array}$ & $\begin{array}{l}\text { Perkinsus } \\
\text { chesapeaki } \\
\text { isolates }\end{array}$ & $\begin{array}{l}\text { Isolate } \\
\text { ATCC no. }\end{array}$ \\
\hline 2 & Macoma balthica & & 3 & \\
\hline 7 & $\begin{array}{l}\text { Crassostrea virginica } \\
\text { Mya arenaria } \\
\text { Tagelus plebeius } \\
\text { Rangia cuneata* }\end{array}$ & ica & $\begin{array}{l}5 \\
2 \\
4\end{array}$ & $\begin{array}{l}\text { PRA-199 } \\
\text { PRA-200 }\end{array}$ \\
\hline 8 & Mya arenaria & & 1 & \\
\hline 9 & $\begin{array}{l}\text { Crassostrea virginica } \\
\text { Mya arenaria } \\
\text { Macoma balthica } \\
\text { Mulinia lateralis* }\end{array}$ & ica & $\begin{array}{l}1 \\
2 \\
2\end{array}$ & $\begin{array}{l}\text { PRA-201 } \\
\text { PRA-202 }\end{array}$ \\
\hline 11 & Mya arenaria & & 2 & $\begin{array}{l}\text { PRA-65 } \\
\text { PRA-66 }\end{array}$ \\
\hline
\end{tabular}

specific PCR assay of clam DNAs that amplified with the genus-specific primer set but neither of the species-specific primer sets were cloned, sequenced, and determined to be $P$. chesapeaki-ITS region sequences.

Based on PCR results, only a single Mya arenaria clam $(0.2 \%$ of 457 clams $)$ that was collected from the James River, Virginia (Fig. 1, Site 1) harbored an apparent Perkinsus marinus infection, and there was no evidence of a $P$. chesapeaki co-infection in that clam. The Perkinsus genus-specific PCR assay product from that clam's DNA was cloned and sequenced, and the sequences were deposited in GenBank (Table 3). Both sequenced clones contained ITS-region sequences unique to $P$. marinus. No $P$. chesapeaki sequences were detected in DNAs from this clam, by either the $P$. chesapeaki-specific PCR assay, or by sequence analysis of amplification products resulting from the genusspecific PCR assay. In the same clam sample from the

Table 3. GenBank accession numbers for the internal transcribed spacer (ITS) region and large subunit ribosomal RNA (LSU rRNA) gene sequences obtained from DNA isolated from Mya arenaria tissue that was PCR-positive for Perkinsus marinus, and from several Perkinsus spp. in vitro isolates propagated from Chesapeake Bay oysters and clams

\begin{tabular}{|c|c|c|c|c|c|}
\hline Site no. & $\begin{array}{l}\text { Isolate code } \\
\text { (ATCC no.) }\end{array}$ & $\begin{array}{l}\text { No. of ITS region } \\
\text { clones sequenced }\end{array}$ & $\begin{array}{c}\text { GenBank } \\
\text { accession no. }\end{array}$ & $\begin{array}{c}\text { No. of LSU rRNA } \\
\text { gene clones sequenced }\end{array}$ & $\begin{array}{c}\text { GenBank } \\
\text { accession no. }\end{array}$ \\
\hline \multicolumn{6}{|c|}{ P. marinus } \\
\hline 1 & M. arenaria host tissue & 2 & $\begin{array}{l}\text { EU919502 } \\
\text { EU919503 }\end{array}$ & & \\
\hline 7 & PXBICv-25/B9/C5 & 2 & $\begin{array}{l}\text { EU919509 } \\
\text { EU919510 }\end{array}$ & & \\
\hline 9 & EBPICv-15/H6/G5 & 5 & $\begin{array}{l}\text { EU919504- } \\
\text { EU919508 }\end{array}$ & 2 & $\begin{array}{l}\text { EU919449 } \\
\text { EU919450 }\end{array}$ \\
\hline \multicolumn{6}{|c|}{ P. chesapeaki } \\
\hline 2 & YRKCMb-1/G2/G8 & 5 & $\begin{array}{l}\text { EU919497- } \\
\text { EU919501 }\end{array}$ & 1 & EU919452 \\
\hline 7 & PXBIMa-5/G1/D12 & 1 & EU919484 & & \\
\hline 7 & PXBIMa-10/D10/E4 & 6 & $\begin{array}{l}\text { EU919485- } \\
\text { EU919490 } \\
\text { EU919463 }\end{array}$ & 2 & $\begin{array}{l}\text { EU919453 } \\
\text { EU919463 }\end{array}$ \\
\hline 7 & PXSATp-6/A7/A8 & 4 & $\begin{array}{l}\text { EU919493- } \\
\text { EU919496 }\end{array}$ & 1 & EU919456 \\
\hline 7 & $\begin{array}{l}\text { PXDCRC-5/D12/F10 } \\
\text { (ATCC PRA-200) }\end{array}$ & 2 & $\begin{array}{l}\text { EU919491 } \\
\text { EU919492 }\end{array}$ & & \\
\hline 8 & CRBSTp-9 & 5 & $\begin{array}{l}\text { EU919464- } \\
\text { EU919468 }\end{array}$ & & \\
\hline 8 & CRBSTp-9/E9/E1 & 1 & EU919469 & 4 & $\begin{array}{l}\text { EU919454 } \\
\text { EU919459 } \\
\text { EU919460 } \\
\text { EU919462 }\end{array}$ \\
\hline 9 & EBPIMa-2/C10/E1 & 5 & $\begin{array}{l}\text { EU919470- } \\
\text { EU919474 }\end{array}$ & 3 & $\begin{array}{l}\text { EU919451 } \\
\text { EU919455 } \\
\text { EU919461 }\end{array}$ \\
\hline 9 & EBNPMb-1/E2/E5 & 4 & $\begin{array}{l}\text { EU919475- } \\
\text { EU919478 }\end{array}$ & & \\
\hline 9 & EBNPMb-2/B5/D12 & 1 & EU919479 & 2 & $\begin{array}{l}\text { EU919457 } \\
\text { EU919458 }\end{array}$ \\
\hline 9 & $\begin{array}{l}\text { EBNPMl-4/E3/E10 } \\
\text { (ATCC PRA-202) }\end{array}$ & 4 & $\begin{array}{l}\text { EU919485- } \\
\text { EU919490 }\end{array}$ & & \\
\hline
\end{tabular}


Table 4. Estimates of Perkinsus sp. prevalence among 5 species of clams from Chesapeake Bay region waters using 3 different assays including the genus-specific Ray's fluid thioglycollate medium (RFTM) assay, a Perkinsus genus-specific internal transcribed spacer (ITS) PCR assay, and a P. chesapeaki-specific ITS-PCR assay. Among the 457 clams tested, only a single Mya arenaria was PCR-positive for P. marinus

\begin{tabular}{|c|c|c|c|c|c|c|c|}
\hline \multirow[t]{2}{*}{ Host clam } & \multirow[t]{2}{*}{$\begin{array}{l}\text { Samples } \\
\text { tested (n) }\end{array}$} & \multicolumn{2}{|c|}{$\begin{array}{c}\text { Genus Perkinsus } \\
\text { RFTM }\end{array}$} & \multicolumn{2}{|c|}{$\begin{array}{c}\text { Genus Perkinsus } \\
\text { ITS-PCR }\end{array}$} & \multicolumn{2}{|c|}{$\begin{array}{l}\text { P. chesapeaki } \\
\text { ITS-PCR }\end{array}$} \\
\hline & & $(\%)$ & (n) & $(\%)$ & (n) & $(\%)$ & (n) \\
\hline Mya arenaria & 200 & 75 & $(150)$ & 66 & $(132)$ & 39 & $(78)$ \\
\hline Tagelus plebeius & 157 & 68 & $(107)$ & 57 & $(89)$ & 53 & (83) \\
\hline Macoma balthica & 36 & 50 & $(18)$ & 78 & $(28)$ & 78 & $(28)$ \\
\hline Mercenaria mercenaria & 60 & 2 & $(1)$ & 0 & $(0)$ & 0 & $(0)$ \\
\hline Cyrtopleura costata & 4 & 100 & $(4)$ & 100 & $(4)$ & 75 & (3) \\
\hline Total & 457 & 61 & $(280)$ & 55 & $(253)$ & 42 & (192) \\
\hline
\end{tabular}

James River, 4 other $M$. arenaria individuals were PCR-positive for P. chesapeaki, but not for P. marinus, while the Perkinsus genus-specific PCR assay was positive among 17 of 25 (68\%) individual clams.

Estimates of Perkinsus sp. infection prevalences by RFTM and molecular assays used for the present study were generally comparable (Table 4). Relative performances of the 3 assays that were used for diagnoses of Perkinsus sp. infections among clams suggest that the proportion of infections detected by RFTM assays was often greater than or equal to the proportions of infections detected by either genus- or species-specific PCR assays used on DNA samples from the same clams (Table 4). However, among samples of Macoma balthica clams that were tested, both PCR assays similarly detected substantially more infections than RFTM assays. In addition, RFTM assays also detected Perkinsus sp. infections in $100 \%$ of tested Mulinia lateralis (2 of 2) and Rangia cuneata (12 of 12) clams, from which no tissues were obtained for molecular analyses (Table 1), but from which only $P$. chesapeaki isolates were propagated in vitro (Table 2). ITS region sequences were obtained from these isolates and deposited in GenBank (Table 3).

Despite close sympatric cohabitation with Perkinsus marinus-infected oysters in Virginia waters, only 1 of $60(2 \%)$ tested Mercenaria mercenaria clams harbored an apparent, low-intensity Perkinsus sp. infection, based on an RFTM assay result in which 2 Perkinsus sp. hypnospore cells were detected in that clam tissue sample. As indicated in Tables $1 \& 4$, this RFTM assay result was not confirmed by either Perkinsus genusspecific PCR or species-specific PCR assay. Mean infection intensities (Bush et al. 1997) were determined for each sample (Table 1 ) and at several sites $(4,8,9$, and 10) were determined to be moderate to high $(>3.0)$ in Crassostrea virginica harboring $P$. marinus as determined by the species-specific PCR assay; yet $P$. mari- nus was not detected in any clams at these sites. Likewise, at Bolingbroke Sands (Site 9) in the Choptank River, samples of both Mya arenaria and Tagelus plebius had $100 \%$ prevalences and moderately high mean infection intensities (4.2 and 3.6, respectively) as determined by the RFTM assay, and presumably entirely due to $P$. chesapeaki based on the PCR results; $P$. chesapeaki was not detected by the species-specific PCR assay in $C$. virginica collected at that site.

Overall, 24 in vitro isolates obtained from 6 species of Chesapeake Bay clams were all identified as Perkinsus chesapeaki (Tables $2 \& 3$ ) based on PCR assay results and sequencing. The ITS region and LSU rRNA gene sequences from several isolates were deposited in GenBank (Table 3). Perkinsus chesapeaki in vitro isolates were propagated, cloned, and cryopreserved from both Mulinia lateralis $(\mathrm{n}=2)$ and Rangia cuneata $(\mathrm{n}=4)$ clams, from which neither $P$. chesapeaki infections nor in vitro isolates have been previously reported. Monoclonal and polyclonal $P$. chesapeaki isolate strains from $M$. lateralis and $R$. cuneata were deposited in the American Type Culture Collection (www.atcc.org) for public distribution, with the respective deposit numbers of ATCC PRA-202, ATCC PRA-201, ATCC PRA-200, and ATCC PRA-199. Select ITS region and LSU rRNA gene PCR amplification products from in vitro isolate DNAs were sequenced, and the resulting sequences were deposited in GenBank (Table 3).

Control hybridization trials indicated that the Perkinsus chesapeaki-specific DIG-labeled probe PchesLSU485 was sensitive and specific, in that hybridization was observed only in parasite cells in the $P$. chesapeaki-infected $M$. arenaria and not in the reference tissues infected by other Perkinsus species. Likewise, testing of the $P$. marinus-specific and $P$. chesapeaki-specific probe cocktails indicated strong and specific hybridization only in cells of the targeted species (Figs. 2 \& 3). 

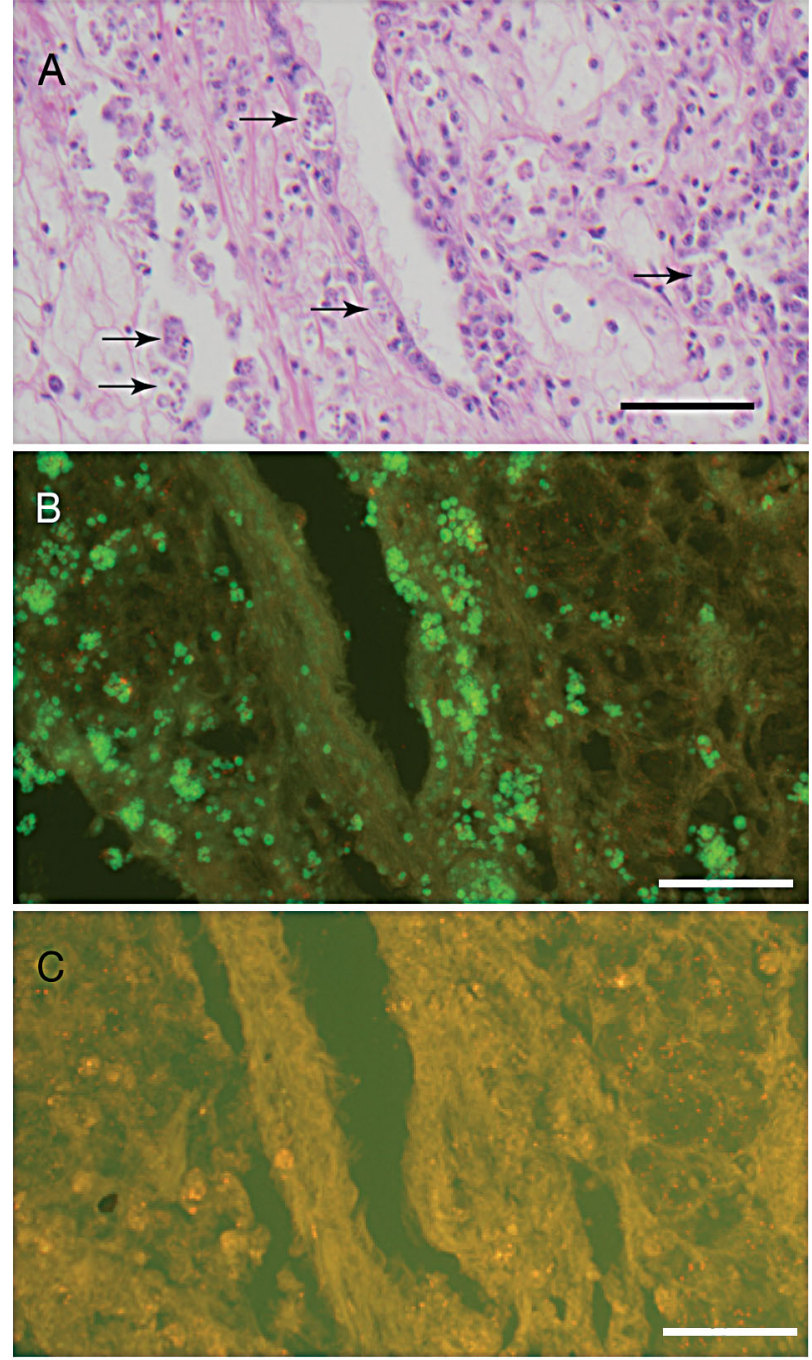

Fig. 2. Perkinsus marinus infecting Crassostrea virginica. Adjacent histological sections from an infected oyster. (A) H\&Estained section through gonoduct, mantle, and gonad showing many clusters of replicating $P$. marinus cells (arrows). (B) Fluorescence in situ hybridization with a cocktail of $3 P$. marinus-specific probes, PmarLSU-181, PmarLSU-420, and PmarLSU-560, each labeled with Alexa Fluor 488. Green fluorescence identifies labeled $P$. marinus cells. (C) No-probe negative control. Scale bars $=20 \mu \mathrm{m}$

Perkinsus genus- and species-specific ISH assays were done on histological sections of 6 Crassostrea virginica for which PCR results indicated the presence of both $P$. chesapeaki and P. marinus. Both the DIG-ISH and FISH assays confirmed the presence of Perkinsus marinus in the tissues of all of these oysters, but results using the $P$. chesapeaki DIG probe and Alexa Fluor 594 probe cocktails were equivocal, without definitive identification of hybridizing $P$. chesapeaki cells. Overall, the ISH results clearly indicated that $P$. marinus was the most abundant of the 2 parasites, where co-
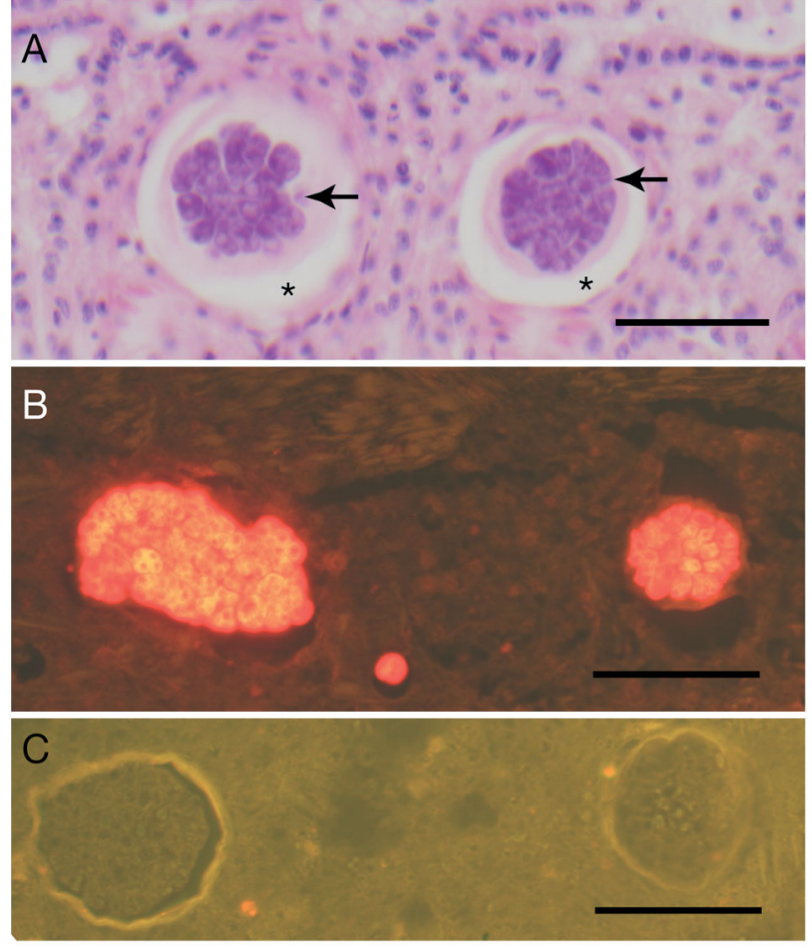

Fig. 3. Perkinsus chesapeaki infecting Mya arenaria. Adjacent histological sections of gill in an infected clam. (A) H\&Estained granulomatous gill connective tissue lesions showing replicating $P$. chesapeaki cells (arrows) surrounded by an acellular matrix and space $\left({ }^{*}\right)$. Scale bar $=40 \mu \mathrm{m}$. (B) Fluorescence in situ hybridization with a cocktail of 2 P. chesapeakispecific probes, PchesLSU-485 and PchesLSU-690, each labeled with Alexa Fluor 594. Red fluorescence identifies labeled P. chesapeaki cells. Scale bar $=50 \mu \mathrm{m}$. (C) No-probe negative control. Scale bar $=40 \mu \mathrm{m}$

infections among oyster hosts were suggested by the PCR assays (Fig. 4).

FISH assays using the Perkinsus chesapeaki-specific probe cocktail indicated hybridization to parasite cells in histological sections from both Cyrtopleura costata clam hosts that were tested, a species from which $P$. chesapeaki infections have not been reported previously. Hybridization to a cluster of apparent proliferating $P$. chesapeaki cells was observed in gill tissue of one clam (Fig. 5).

The FISH assay results from the single Mya arenaria clam that was uniquely positive among all clam samples in the Perkinsus marinus-specific PCR assay confirmed that this clam was infected by $P$. marinus. The $P$. marinus-specific probe cocktail, but not the P. chesapeaki-specific probe cocktail, hybridized to parasite cells among connective tissues adjacent to digestive epithelia in histological sections, where there was also strong evidence of phagocytosis of proliferating P. marinus cells by clam hemocytes (Fig. 6). 

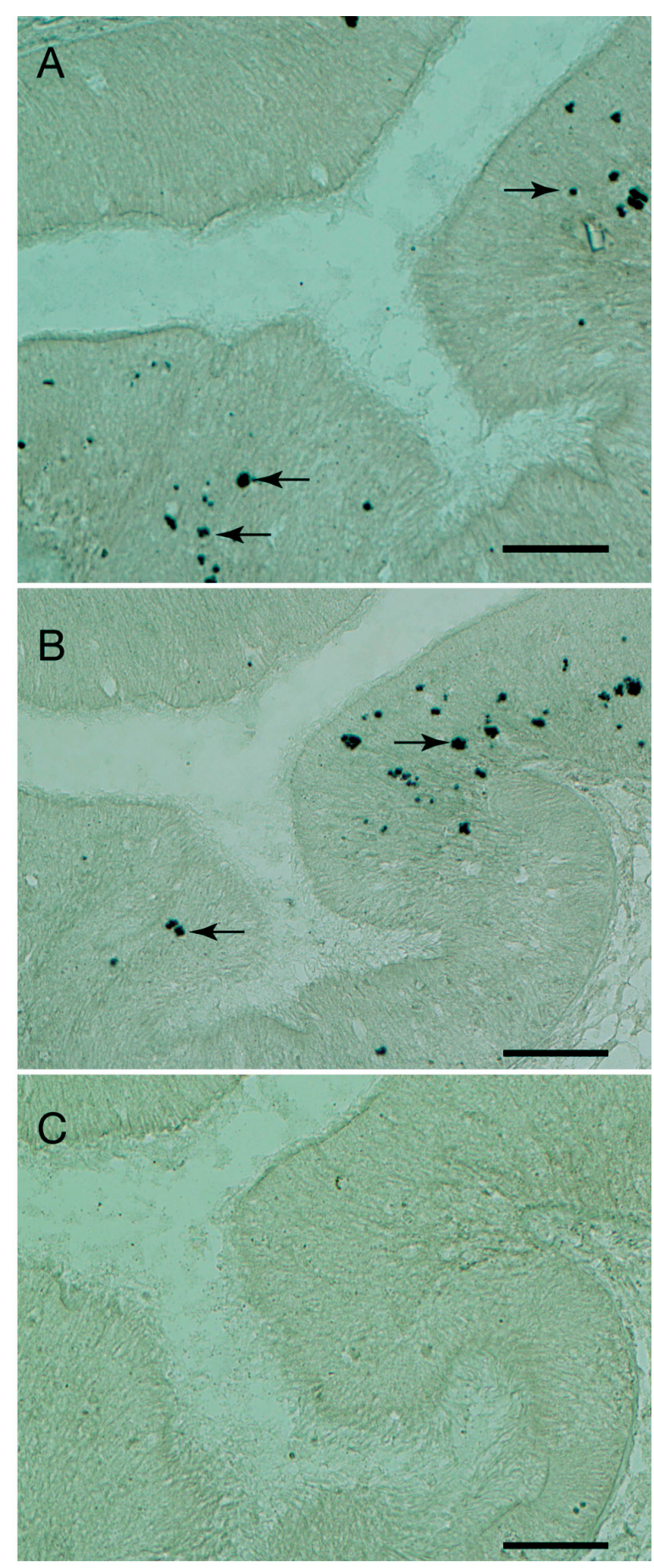

Fig. 4. Perkinsus spp. infecting Crassostrea virginica. In situ hybridization of histological sections from an oyster that was PCR-positive for both $P$. marinus and $P$. chesapeaki, with digoxigenin-labeled probes. (A) Perkinsus genus-specific probe, PerkspSSU-700DIG, showing labeled Perkinsus sp. cells (arrows) within intestine epithelium. (B) Hybridization of the $P$. marinus-specific probe PmarLSU-181DIG showing reacting cells (arrows) in a section adjacent to that shown in (A). (C) Same lesion in another adjacent section where the $P$. chesapeaki-specific probe, PchesLSU-485DIG, failed to label any pathogen cells. Scale bars $=50 \mu \mathrm{m}$
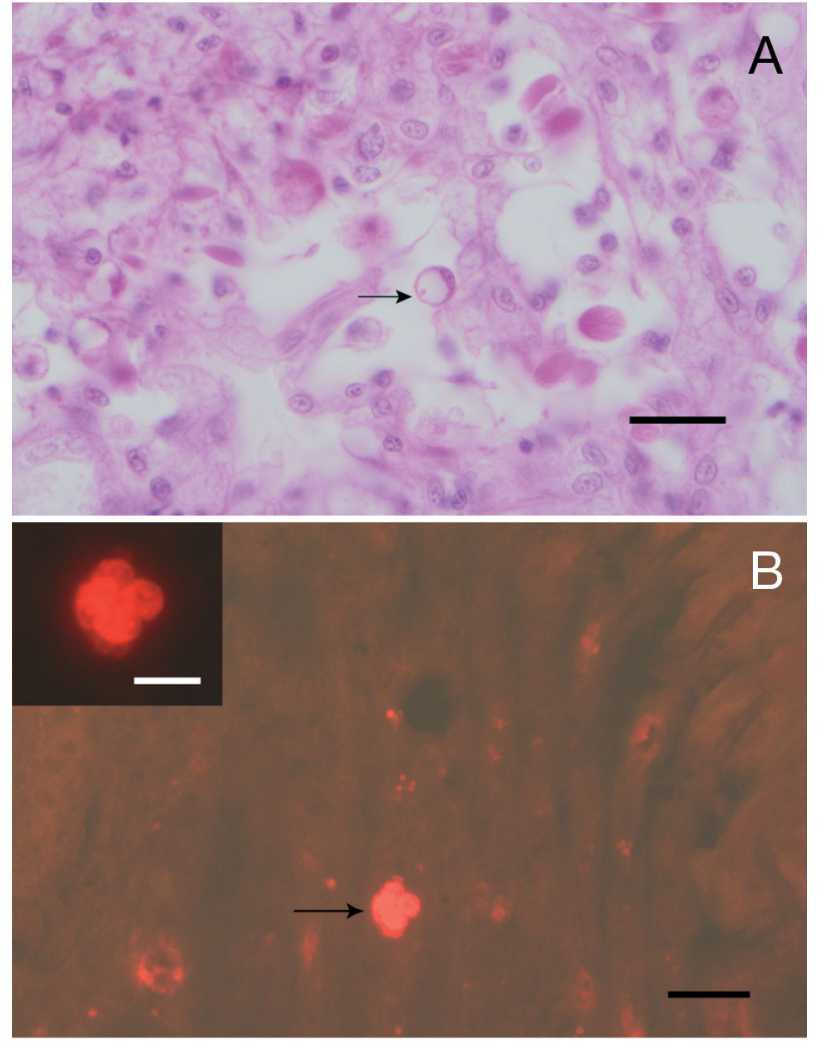

Fig. 5. Perkinsus chesapeaki infecting Cyrtopleura costata. (A) H\&E-stained gill tissue of C. costata showing a Perkinsus sp. cell (arrow), but no evidence of a host reaction in the tissue. Scale bar $=20 \mu \mathrm{m}$. (B) Fluorescence in situ hybridization of $C$. costata gill tissue with a cocktail of $2 P$. chesapeakispecific probes, PchesLSU-485 and PchesLSU-690, each labeled with Alexa Fluor 594, showing positive reactions (red signal) with a cluster of 4 apparently proliferating $P$. chesapeaki cells (arrow). Scale bar $=20 \mu \mathrm{m}$. Inset (scale bar $=$ $10 \mu \mathrm{m}$ ) shows higher magnification of the multi-cell cluster

\section{DISCUSSION}

Although Perkinsus marinus and P. chesapeaki are both experimentally infective for several sympatric Chesapeake Bay oyster and clam hosts (Dungan et al. 2007), results from the present study of wild Chesapeake Bay region oysters and clams reveal that under natural conditions, those co-endemic Perkinsus species are strongly partitioned between sympatric molluscan hosts. Despite demonstrated capabilities for direct waterborne transmission of $P$. marinus infections via cells disseminated from infected oysters (Ray \& Chandler 1955, Ragone Calvo et al. 2003) and the close physical proximity of the sympatric mollusc species sampled, our results show that $P$. marinus rarely infects clam hosts. Results indicate that $P$. marinus almost exclusively infects wild Crassostrea virginica oysters, and that $P$. chesapeaki predominantly infects at least 6 


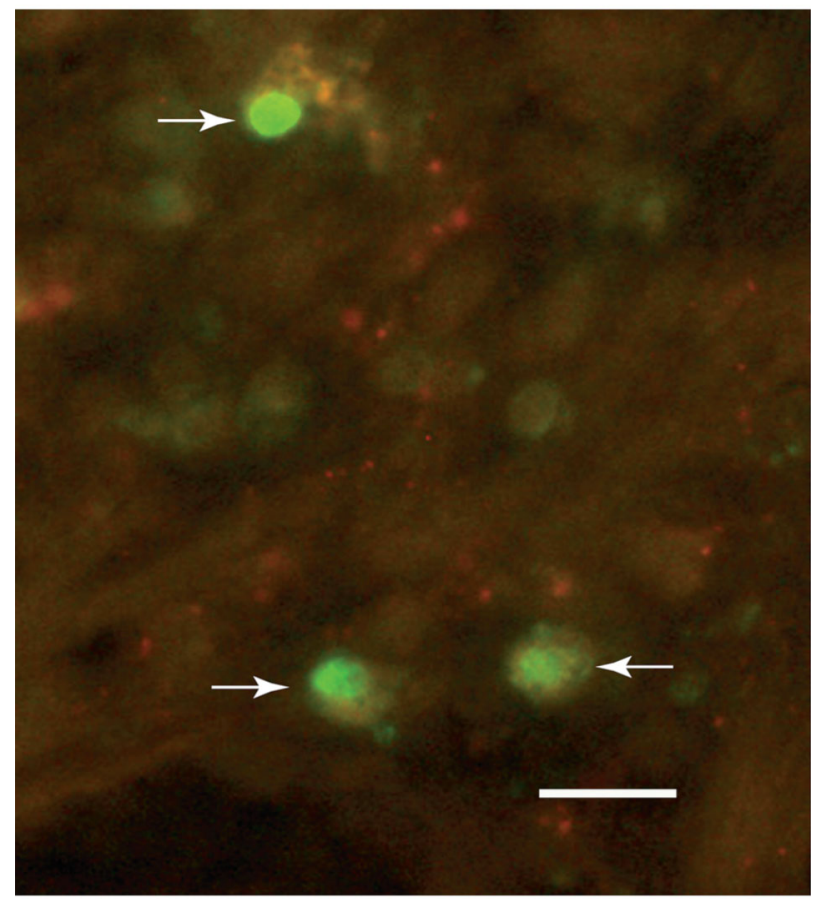

Fig. 6. Perkinsus marinus infecting Mya arenaria. Fluorescence in situ hybridization on a histological section of a rare clam that was PCR-positive for $P$. marinus. The section was probed with a cocktail of $3 P$. marinus-specific probes, PmarLSU-181, PmarLSU-420, and PmarLSU-560, each labeled with Alexa Fluor 488, showing positive reactions (green signal) with 3 cells (arrows). At least the 2 lower clusters of small $P$. marinus cells appear to be phagocytized within clam hemocytes. Scale bar $=20 \mu \mathrm{m}$

clam species, among which it was the only Perkinsus sp. detected in $99 \%$ of infected clams.

These field results strongly qualify results from our previous laboratory challenge study in which both Perkinsus marinus and $P$. chesapeaki infections were readily acquired experimentally at 33 to $100 \%$ incidences among both oysters and clams, following extended exposures to high pathogen doses (Dungan et al. 2007). It is not clear what mechanisms might yield the different functional host specificities of these parasites under natural and experimental conditions. Since the referenced laboratory experiments did not include simultaneous co-challenges with both parasite species, possible effects of competition between Perkinsus species for specific hosts were not assessed. Results from the present study suggest that at most sampling sites, all potential hosts were exposed to both parasite species, given the consistently high infection prevalences by their respective pathogens that were observed among sympatric local oysters and clams.

It is possible that oysters and clams express pathogen-specific defenses that are differentially effective against one pathogen or another, and that such differential defenses were compromised or overwhelmed by intense artificial infection pressures and conditions in our previous laboratory study (Dungan et al. 2007). In addition, the reported experimental laboratory challenges were conducted with cultured in vitro trophozoite cells, whose infectivities may differ from those of other forms of the pathogen cells, such as zoospores (Perkins 1996), which may be the more common infectious cell type encountered and modulated by bivalve mollusc hosts under natural conditions. In addition, clams burrow into the sediments, while oysters typically attach to substrates on and above those sediments. Therefore, it is possible that varying infectivities of Perkinsus marinus and $P$. chesapeaki among these different hosts may result from unknown mechanistic factors or conditions associated with specific habitat niches. Nonetheless, it is clear from the present field study results that there is differential susceptibility to $P$. marinus and $P$. chesapeaki among wild oysters and clams living in close benthic proximity to each other throughout the Chesapeake Bay region.

Given that no exclusive Perkinsus chesapeaki infections were detected by the Perkinsus speciesspecific PCR assays we conducted on 279 Crassostrea virginica oysters from 11 Chesapeake Bay region sites, it does not appear that RFTM assays have historically or currently overestimated $P$. marinus infection prevalences or disease impacts in Chesapeake Bay oysters. Positive results from early RFTM assays on Chesapeake Bay clams were interpreted to reflect P. marinus infections (Andrews 1954, Ray \& Chandler 1955), but our results suggest that $P$. chesapeaki was the probable infective species detected in those clams. P. chesapeaki was relatively recently described from clam hosts, and was determined to be a prevalent parasite of several clam species (Burreson et al. 2005). Results of the present study clearly demonstrate its widespread and generally exclusive infectivity for an expanded range of at least 6 species of wild Chesapeake Bay clams. There are few reports of Perkinsus sp. infections among Mercenaria mercenaria commercial clams (Andrews 1954, Ray 1954, Coss et al. 2001, McCoy et al. 2007, Pecher et al. 2008), and results of the present study that also show only rare and light infections among tested $M$. mercenaria clams are consistent with those of earlier investigations by Ford (2001), which concluded that Perkinsus sp. infections in $M$. mercenaria are rare and their impacts minimal.

Although overall the infection prevalences estimated by our RFTM and molecular assays were generally comparable, prevalence estimates by RFTM assays for Perkinsus sp. infections in some clam species, particularly in Mya arenaria, were sometimes higher than 
prevalence estimates by the PCR assays (see Table 4). The $P$. chesapeaki-specific PCR assay estimated a lower infection prevalence $(39 \%)$ in $M$. arenaria than either the genus-specific PCR assay (66\%) or the RFTM assay (75\%). Therefore, infection prevalences in susceptible clams may be underestimated by our $P$. chesapeaki-specific PCR assays, which these results suggest is slightly less sensitive than the Perkinsus genus-specific PCR assay.

Alternatively, there could be additional undescribed Perkinsus species that infect Chesapeake Bay region clams, which are detected by the RFTM and Perkinsus genus-specific PCR assay but not by the P. marinus or $P$. chesapeaki-specific assays. Sequence analysis of several PCR products resulting from the Perkinsus genus-specific assays of clams indicated that $P$. chesapeaki was present but not always detected by the $P$. chesapeaki-specific PCR assay. Since only P. chesapeaki isolates were obtained from the variety of clam species collected from several locations for the present study, it is unlikely that there are undescribed Perkinsus species infecting these clams.

Results from another study using Perkinsus genusspecific and species-specific PCR assays also indicated a lower sensitivity with the species-specific assays (Pecher et al. 2008). Some apparent detection differences between the PCR and RFTM assays for different individual hosts may reflect sampling error artifacts, which may result from differences in the type and quantity of tissues sampled for different assays (Bushek et al. 2008). Typically, smaller tissue samples are used for extracting PCR template DNAs, relative to tissue volumes analyzed by RFTM assays. Only small tissue pieces $\left(<0.25 \mathrm{~cm}^{3}\right)$ were used in the Qiagen DNA extraction protocol employed for the present study, and then only 5 to $300 \mathrm{ng}$ of extracted sample DNAs were analyzed by our PCR assays. Although the molecular assays are generally quite sensitive, it is possible that tissues extracted for PCR template DNAs from infected hosts with low-intensity or focal lesions contained few, if any, Perkinsus sp. cells. Gill and mantle tissues were sampled from clams for the RFTM assays, and rectum and gill tissues from oysters. In contrast, tissue samples preserved in ethanol for the DNA assays all included portions of the mantle, gill, gonad, and visceral mass. In addition, for a particular individual, independent tissue samples were used for the DNA isolations and RFTM assays. Therefore, in a lightly infected individual with a limited number of parasite cells heterogeneously distributed among host tissues, the probability of their inclusion in subsamples for both assays is reduced.

Numerous ISH assays using both Perkinsus marinusand $P$. chesapeaki-specific probes were conducted on tissues from oysters for which PCR assay results suggested co-infections by both parasites. Results consistently showed that $P$. marinus cells were far more abundant than $P$. chesapeaki cells, which were only rarely located in situ. Consistent results of $P$. marinusspecific FISH assays, P. marinus-specific PCR assays, and sequence analysis of PCR products obtained from the Perkinsus genus-specific PCR assay collectively confirm a rare infection by $P$. marinus of a single Mya arenaria clam. This is the first empirical, in situ confirmation of a $P$. marinus infection in a Chesapeake Bay clam, and supports a previous report of PCR evidence for such infections among Macoma balthica clams (Coss et al. 2001), as well as the report of an undeposited $P$. marinus isolate (H49) that was propagated from a Mya arenaria hemolymph sample (Kotob et al. 1999). Overall, however, through rigorous analyses with several assays, results of the present study clearly indicate that $P$. marinus is primarily an oyster parasite, while $P$. chesapeaki infections predominate among Chesapeake Bay clams.

Results from wild Chesapeake Bay molluscs are also consistent with the exclusive historic reports of Perkinsus marinus in vitro isolates propagated from Chesapeake Bay oysters, and a nearly exclusive record of $P$. chesapeaki in vitro isolates propagated from Chesapeake Bay clams (La Peyre et al. 2006). The same trend is reflected in the identities of 30 in vitro Perkinsus spp. isolates propagated from diverse mollusc hosts during the present study. These results further qualify our previous experimental results (Dungan et al. 2007) showing absolute cross-infectivities by $P$. marinus and $P$. chesapeaki in vitro isolate cells for the same Crassostrea virginica oysters and Mya arenaria and Macoma balthica clams, which are among the wild mollusc species sampled and analyzed by the present investigation. The mechanisms that affect the functional host-resource partitioning reported here between similar parasite species capable of crossinfecting each other's cognate hosts beg resolution through studies now feasible with the molecular tools described here.

Acknowledgements. This research was funded in part by Sea Grant Oyster Disease Research Program award NA16RG1697 (VA-OD 0104), and by NOAA Chesapeake Bay Fisheries Research Program award NA17FU1652. Reported results and their interpretations are solely those of the authors. Expert sample collections by Maryland DNR biologists M. Homer, M. Tarnowski, and R. Bussell, and by VIMS student K. Delano are gratefully acknowledged. Critical PCR and ISH assays were performed by K. Hudson, J. Xiao, N. Stokes, A. MacIntyre and J. Moss (VIMS); in vitro Perkinsus sp. isolates were propagated and cloned by R. Hamilton (MDDNR-Oxford); and H. Kelsey (NOAA-Oxford) generously contributed Fig. 1. This manuscript is VIMS contribution \#2983. 


\section{LITERATURE CITED}

Andrews JD (1954) Notes on fungus parasites of bivalve mollusks in Chesapeake Bay. Proc Natl Shellfish Assoc 45:157-163

- Audemard C, Reece KS, Burreson EM (2004) Real-time PCR for detection and quantification of the protistan parasite Perkinsus marinus in environmental waters. Appl Environ Microbiol 70:6611-6618

Burreson EM (2008) Misuse of PCR assay for diagnosis of mollusc protistan infections. Dis Aquat Org 80:81-83

> Burreson EM, Reece KS, Dungan CF (2005) Molecular, morphological, and experimental evidence support the synonymy of Perkinsus chesapeaki and Perkinsus andrewsi. J Eukaryot Microbiol 52:258-270

> Bush AO, Lafferty KD, Lotz JM, Shostak AW (1997) Parasitology meets ecology on its own terms: Margolis et al. revisited. J Parasitol 83:575-583

Bushek D, Landau B, Scarpa E (2008) Perkinsus chesapeaki in stout razor clams Tagelus plebeius from Delaware Bay. Dis Aquat Org 78:243-247

Carnegie RB, Burreson EM, Hine PM, Stokes NA, Audemard C, Bishop MJ, Peterson CH (2006) Bonamia perspora n. sp. (Haplosporidia), a parasite of the oyster Ostreola equestris, is the first Bonamia species known to produce spores. J Eukaryot Microbiol 53:232-245

Casas SM, Villalba A, Reece KS (2002) Study of perkinsosis in the carpet shell clam Tapes decussatus in Galicia (NW Spain). I. Identification of the aetiological agent and in vitro modulation of zoosporulation by temperature and salinity. Dis Aquat Org 50:51-63

> Coss CA, Robledo JAF, Ruiz GM, Vasta GR (2001) Description of Perkinsus andrewsi n. sp. isolated from the Baltic clam (Macoma balthica) by characterization of the ribosomal RNA locus, and development of a species-specific PCR-based diagnostic assay. J Eukaryot Microbiol 48:52-61

Dungan CF, Hamilton RM, Hudson KL, McCollough CB, Reece KS (2002) Two epizootic diseases in Chesapeake Bay commercial clams Mya arenaria and Tagelus plebeius. Dis Aquat Org 50:67-78

Dungan CF, Hamilton RM, Reece KS, Burreson EM (2007) Experimental cross-infections by Perkinsus marinus and $P$. chesapeaki in three species of sympatric Chesapeake Bay oysters and clams. Dis Aquat Org 76:67-75

Elston RA, Dungan CF, Meyers TR, Reece KS (2004) Perkinsus sp. infection risk for Manila clams, Venerupis philippinarum (A. Adams and Reeve, 1850) on the Pacific coast of North and Central America. J Shellfish Res 23:101-105

Ford SE (2001) Pests, parasites, diseases, and defense mechanisms of the hard clam, Mercenaria mercenaria. In: Kraeuter JN, Castagna M (eds) Biology of the hard clam. Elsevier, Amsterdam, p 591-628

Gauthier JD, Miller CR, Wilbur AE (2006) Taqman MGB realtime PCR approach to quantification of Perkinsus marinus and Perkinsus spp. in oysters. J Shellfish Res 25:619-624

Kotob SI, McLaughlin SM, van Berkum P, Faisal M (1999) Characterization of two Perkinsus spp. from the softshell clam, Mya arenaria, using the small subunit ribosomal RNA gene. J Eukaryot Microbiol 46:439-444

La Peyre JF, Faisal M (1995) Improved method for the initiation of continuous cultures of the oyster pathogen Perkinsus marinus (Apicomplexa). Trans Am Fish Soc 124:144-146

La Peyre M, Casas S, La Peyre J (2006) Salinity effects on viability, metabolic activity, and cellular proliferation of three Perkinsus spp. Dis Aquat Org 71:59-74
Lenaers G, Maroteaux L, Michot B, Herzog M (1989) Dinoflagellates in evolution. A molecular phylogenetic analysis of large subunit ribosomal RNA. J Mol Evol 29:40-51

> Mackin JG, Owen HM, Collier A (1950) Preliminary note on the occurrence of new protistan parasite, Dermocystidium marinum n. sp. in Crassostrea virginica (Gmelin). Science 111:328-329

Marsh AG, Gauthier JD, Vasta GR (1995) Semiquantitative PCR assay for assessing Perkinsus marinus infections in the eastern oyster, Crassostrea virginica. J Parasitol 81: 577-583

> McCoy A, Baker SM, Wright AC (2007) Investigation of Perkinsus spp. in aquacultured hard clams (Mercenaria mercenaria) from the Florida Gulf coast. J Shellfish Res 26:1029-1033

McLaughlin SM, Faisal M (2000) Prevalence of Perkinsus spp. in Chesapeake Bay soft-shell clams, Mya arenaria Linneaeus, 1758 during 1990-1998. J Shellfish Res 19: 349-352

> McLaughlin SM, Tall BD, Shaheen A, El Sayed EE, Faisal M (2000) Zoosporulation of a new Perkinsus species isolated from the gills of the softshell clam Mya arenaria. Parasite $7: 115-122$

> Moss JA, Burreson EM, Reece KS (2006) Advanced Perkinsus marinus infections in Crassostrea ariakensis maintained under laboratory conditions. J Shellfish Res 25:65-72

Pecher WT, Alavi MR, Schott EJ, Feranadez-Robledo JA, Roth L, Berg ST, Vasta GR (2008) Assessment of the northern distribution range of selected Perkinsus species in eastern oysters (Crassostrea virginica) and hard clams (Mercenaria mercenaria) with the use of PCR-based detection assays. J Parasitol 94:410-422

Perkins FO (1996) The structure of Perkinsus marinus (Mackin, Owen and Collier, 1950) Levine, 1978 with comments on taxonomy and phylogeny of Perkinsus spp. J Shellfish Res 15:67-87

Ragone Calvo LM, Dungan CF, Roberson BS, Burreson EM (2003) Systematic evaluation of factors controlling Perkinsus marinus transmission dynamics in lower Chesapeake Bay. Dis Aquat Org 56:75-86

- Ray SM (1952) A culture technique for the diagnosis of infections by Dermocystidium marinum Mackin, Owen, and Collier in oysters. Science 116:360-361

Ray SM (1954) Biological studies of Dermocystidium marinum, a fungus parasite of oysters. The Rice Institute, Houston, TX

Ray SM, Chandler AC (1955) Dermocystidium marinum, a parasite of oysters. Exp Parasitol 4:172-200

Reece KS, Stokes NA (2003) Molecular analysis of a haplosporidian parasite from cultured New Zealand abalone Haliotis iris. Dis Aquat Org 53:61-66

Robledo JAF, Gauthier JD, Coss CA, Wright AC, Vasta GR (1998) Species-specificity and sensitivity of a PCR-based assay for Perkinsus marinus in the eastern oyster, Crassostrea virginica: a comparison with the fluid thioglycollate assay. J Parasitol 84:1237-1244

Shaw BL, Battle HI (1957) The gross and microscopic anatomy of the digestive tract of the oyster Crassostrea virginica (Gmelin). Can J Zool 35:325-347

> Stokes NA, Burreson EM (1995) A sensitive and specific DNA probe for the oyster pathogen Haplosporidium nelsoni. J Eukaryot Microbiol 42:350-357

- Valiulis GA, Mackin JG (1969) Formation of sporangia and zoospores by Labyrinthomyxa sp. parasitic in the clam Macoma balthica. J Invertebr Pathol 14:268-270

> Yarnall HA, Reece KS, Stokes NA, Burreson EM (2000) A quantitative competitive polymerase chain reaction assay for the oyster pathogen Perkinsus marinus. J Parasitol 86:827-837

Submitted: July 28, 2008; Accepted: October 13, 2008

Proofs received from author(s): November 21, 2008 